\title{
Effect of forming parameters on electron beam Surfi-Sculpt protrusion for Ti-6Al-4V
}

\author{
Xichang Wang ${ }^{\mathrm{a}, \mathrm{b}, \mathrm{c}}$, Joseph Ahn ${ }^{\mathrm{b}}$, Qian Bai ${ }^{\mathrm{b}, *}$, Wenjun Lu ${ }^{\mathrm{d}}$, Jianguo Lin ${ }^{\mathrm{b}}$ \\ ${ }^{a}$ Science and Technology on Power Beam Processes Laboratory, \\ Beijing Aeronautical Manufacturing Technology Research Institute, Beijing,100024, China \\ ${ }^{\mathrm{b}}$ Department of Mechanical Engineering, Imperial College London, London, SW7 2AZ, \\ UK Huazhong University of Science and Technology, Wuhan, 430074,China \\ ${ }^{\mathrm{d}}$ Department of Materials, Imperial College London, London, SW7 2AZ,UK
}

\begin{abstract}
The development of electron beam Surfi-Sculpt enables many types of protrusions in a wide range of metallic materials to be tailored. The effect of forming parameters, including heat input and scanning frequency on the quality of protrusions and microstructure evolution were studied. The micro-hardness of heat affected zone was greater than that of the molten zone and parent material. Forming parameters were optimized by comparing the height of the protrusion. This study can provide guidance for an optimum protrusion design.

Keywords: Titanium alloy; Electron beam method; Protrusion; Microstructure; Hardness test
\end{abstract}

*Corresponding author. Tel: 44 (0) 207 5957060; Fax:44(0) 2075947017

E-mail: q.bai08@imperial.ac.uk 


\section{Introduction}

Electron beam Surfi-Sculpt is a novel surface structuring technique developed since 2004 by The Welding Institute (TWI) for advanced applications in many fields [1-6], for example, composite to metal joining, also known as Comeld $^{\mathrm{TM}}$ [7-10], surface coating pre-treatment [11] and manufacture of hydro-dynamically enhanced surfaces [12]. In this process, electron beam is deflected by a controlled magnetic field, which allows the beam to be located at targeting positions on the surface of the metal. As shown in Figure 1a-f, when the beam is moved according to a predefined trajectory, scanning frequency and heat input, the molten metal initially flows in the opposite direction to the beam movement due to the associated surface tension and vapour pressure of the molten metal, and subsequently it is solidified behind the beam once the beam passes through. This process is repeated several times on the same site so that a protrusion can be built up quickly.

Since the Surfi-Sculpt process has shown potential for the use in high efficiency micro-processing for joining of metal and composite materials, surface pre-treatment for coating, surfaces with lower drag resistance [13], hydrophobic effect [14], a wide range of materials have been processed by electron beam Surfi-Sculpt, including titanium alloys, steel, copper, as shown in Figure1g-j. Also, the protrusion size ranges from $10 \mu \mathrm{m}$ to $20 \mathrm{~mm}$, and complex shapes and patterns of protrusions can be precisely tailored $[2,4]$. The process when using high frequency magnetic coil controlling, is very efficient that it only takes around $10 \mathrm{~s}$ to form a protrusion with a height of 1.5 $\mathrm{mm}$. However research of electron beam Surfi-Sculpt process for titanium alloys is limited due to its poor thermal conductivity, as shown in surface treatment processes [15].

It is difficult to efficiently manufacture small protrusions or surface structures for titanium alloys using traditional methods. For example, by using surface roughness processing techniques such as shot peening [16], Electro-Discharge Texturing (EDT) [17] and early laser texturing [18], only limited types of protrusions can be obtained. Research has been carried out using arc welding to manufacture protrusions for stainless steel (cold-metal transfer, CMT) [19], but it was found it is 
difficult to produce protrusions for titanium alloys and the shape of protrusions could not be varied extensively. Surfi-Sculpt process using laser beam with a movable scanner or worktable, can output similar but fewer types of patterns for protrusions on metal surface [20]; however, the processing rate is much slower than that in the electron beam Surfi-Sculpt process, due to the slow response of scanner or worktable in laser beam processing. Furthermore, in electron beam Surfi-Sculpt process vacuum environment can improve the surface quality of work-piece and oxide of titanium alloys can be eliminated [21].

In the electron beam Surfi-Sculpt process for titanium alloys, the metal substrate is subjected to heating, melting, cooling and solidification, and thus microstructures are varied at molten zone, heat affected zone and parent material. Material transfer and piling coupled with thermal cycle occur in this process. Depending on protrusion height, several repeats may be necessary to ensure sufficient materials to be transferred from parent material to the protrusion. Therefore the relationship between scanning frequency and heat input is of importance in this process. In this paper the effect of forming parameters on topography is studied, and the microstructure observation and the micro-hardness test are conducted. The forming parameters in electron beam Surfi-Sculpt process for Ti-6Al-4V is optimised. 


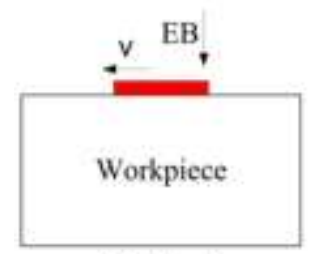

(a) Heat

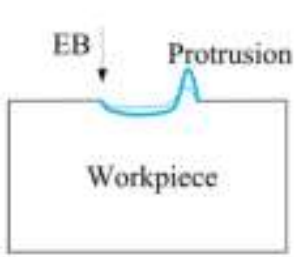

(d) Pile

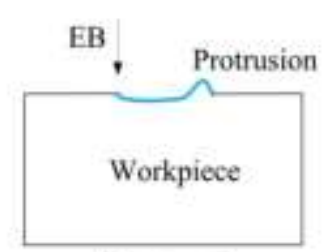

(b) $\mathrm{CoOl}$

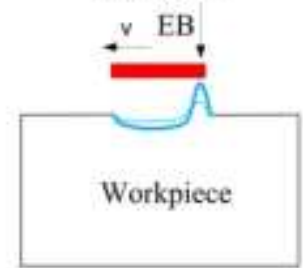

(e) Repeat

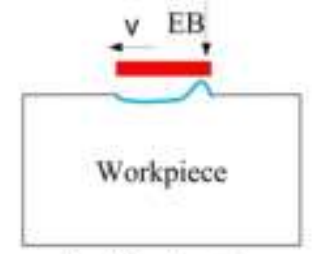

(c) Reheat

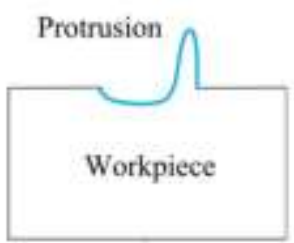

(f) Form
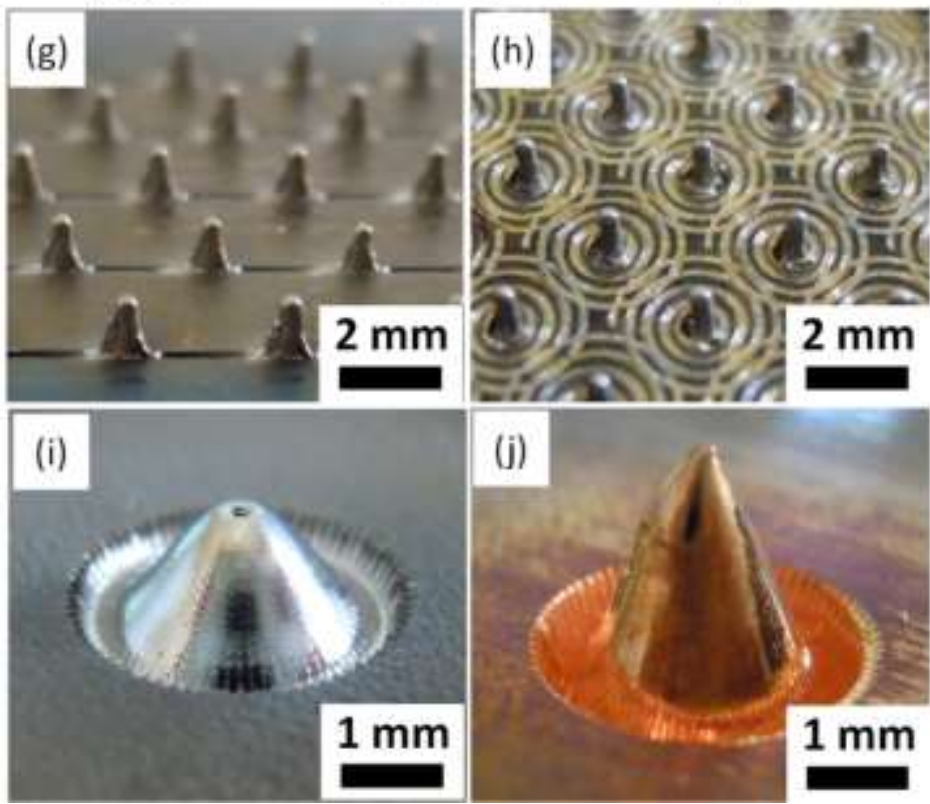

Figure 1.(a)-(f) An illustration of the process of Surfi-Sculpt; (g)-(j) Types of patterns of protrusions manufactured in the Laboratory. The materials are Ti-6Al-4V (g,h), steel (i) and copper (j).

\section{Experimental materials and procedures}

The material used in this research was Ti-6Al-4V titanium alloy. Surfi-Sculpted specimens were manufactured using an electron beam processing machine (ZD150-15MH), with an accelerating voltage of $150 \mathrm{kV}$, beam currents of $1.5,3.5$ and $5 \mathrm{~mA}$, scanning frequencies between 500 and $4500 \mathrm{~Hz}$, and a scanning waveform of Archimedes spirals to determine the path of the electron beam movement, as shown in Fig.2, which included 8 rows and 5 columns. The scanning 
area was $33 \times 30 \mathrm{~mm}$ and 40 protrusions were generated.

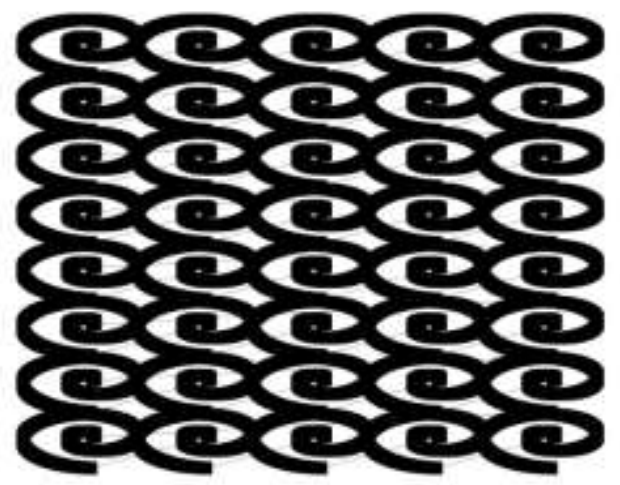

Fig. 2 Scanning waveform of Archimedes spirals

The sample shown in Figure $1 \mathrm{~h}$ was machined down to the centre of the protrusion for microstructure observation and hardness test. An optical microscope (OM, Zeiss Axio ScopeA1) was used for microstructural examination. Energy dispersive X-ray spectroscopy (EDS) in an environmental SEM (Hitachi S-3400N VPSEM) was used to determine chemical elements in different areas, and thus to determine the interface between the HAZ and the parent material. The phases of the specimens were identified using $\mathrm{X}$-ray diffraction with $\mathrm{Cu}$-Ka radiation (PANalytical $\mathrm{X}^{\prime}$ Pert ProMPD). A ZwickRoell Z2.5 Vickers micro-hardness tester was used for hardness measurements with a load of $1 \mathrm{~kg}$ and an interval of $150 \mu \mathrm{m}$.

\section{Results and discussion}

\subsection{Effect of parameters on the height of protrusion}

Parameters used in the electron beam Surfi-Sculpt process are related to the heat source and deflection. The heat source parameters mainly include heat input (it normally denotes the beam current) and processing time. The deflection parameters include scanning frequency and scanning waveform. In this paper, the effect of heat input and scanning frequency on the height of the protrusion was investigated, the protrusion pattern is shown in Figure $1 \mathrm{~h}$.

Figure 2 shows the effect of heat input on the protrusion height. With the increase of beam 
current, $\mathrm{I}_{\mathrm{b}}$, from 1.5 to $5 \mathrm{~mA}$, the protrusion height was increased, and the protrusion growth rate was increased at the beginning of the process and then decreased. When the metal substrate was subjected to a low heat input, e.g. beam current, $\mathrm{I}_{\mathrm{b}}=1.5 \mathrm{~mA}$, the protrusion growth rate was very slow due to a limited amount molten material around the protrusion for piling each time. When the beam current of $5 \mathrm{~mA}$ was used, the protrusion grew quickly to $1 \mathrm{~mm}$ in $3 \mathrm{~s}$. However, the growth rate was decreased with time when using a higher heat input because local heating of the protrusion reduced the surface tension gradient and the molten metal flew easily with lower viscosity. Due to a larger amount of input heat, the molten metal behind the beam remained at relatively high temperature for a prolonged period of time; therefore, it had insufficient time to cool and pile up effectively before the beam reheated the same area. As a result, the protrusion height was increased at a lower rate whereas the root of the protrusion became thicker and a greater overall thermal distortion of the specimen was detected. Hence, it is more suitable to use higher heat input parameters for manufacturing larger protrusions on thicker plates as the effect of thermal distortion will be less significant.

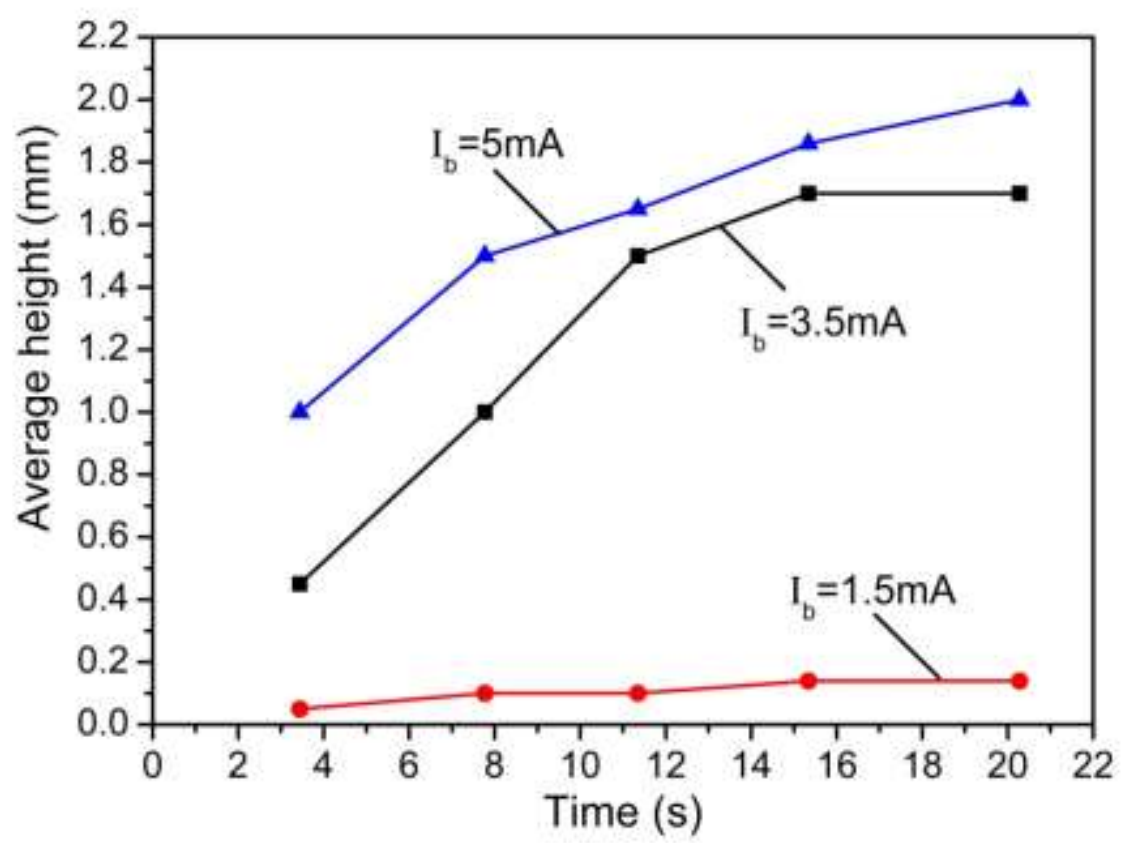

Figure 2.The effect of heat input (beam current, $\mathrm{I}_{\mathrm{b}}, \mathrm{mA}$ ) with $\mathrm{f}=1500 \mathrm{~Hz}$ on the height of protrusion (Accelerating voltage was $150 \mathrm{kV}$ ). 
Figure 3 illustrates the effect of scanning frequency on the protrusion height. At frequencies of $500 \mathrm{~Hz}$ and $750 \mathrm{~Hz}$, the molten metal was cooled and solidified too quickly, and it is difficult to transfer the solidified material to the tip of the protrusion; therefore the increase of the protrusion height was retarded when the beam arrived at the same position in the next iteration. The process at these frequencies was a cycle of melting and solidification of the substrate, little material was transferred from the substrate to the protrusion; therefore the height was only about $0.1 \mathrm{~mm}$. At a frequency of $4500 \mathrm{~Hz}$, the heated metal reached a temperature where it became liquid with low viscosity and the interaction between surface tension and vapour pressure could no longer contribute much to forming protrusion. Even with a longer time at this frequency, the protrusion height of $0.8 \mathrm{~mm}$ was considerably shorter than that produced at $1500 \mathrm{~Hz}$, which was about 1.8 $\mathrm{mm}$.

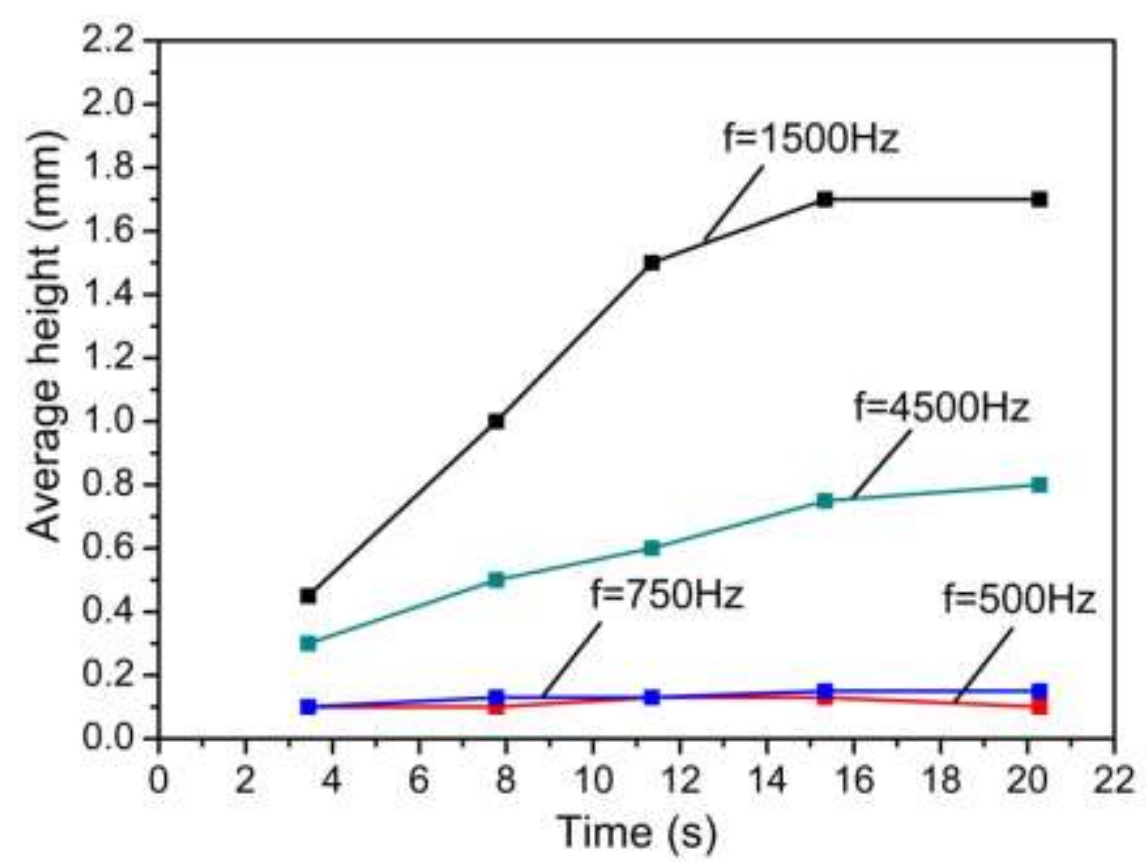

Figure 3. The effect of scanning frequency (f, Hz) with $\mathrm{I}_{\mathrm{b}}=3.5 \mathrm{~mA}$ on the height of protrusion (Accelerating voltage was $150 \mathrm{kV}$ ).

\subsection{Topography}

Fig. 3 shows the topography of specimen surface protrusions. The molten materials was pushed 
to the top of the protrusions along the path of the electron beam, which was shown in the Fig.2. The material over the surface will keep the same volume of the groove. That is to say, electron beam surfi-sculpt is a process of material transferring after melting, which cannot add or lose the weight of specimen.
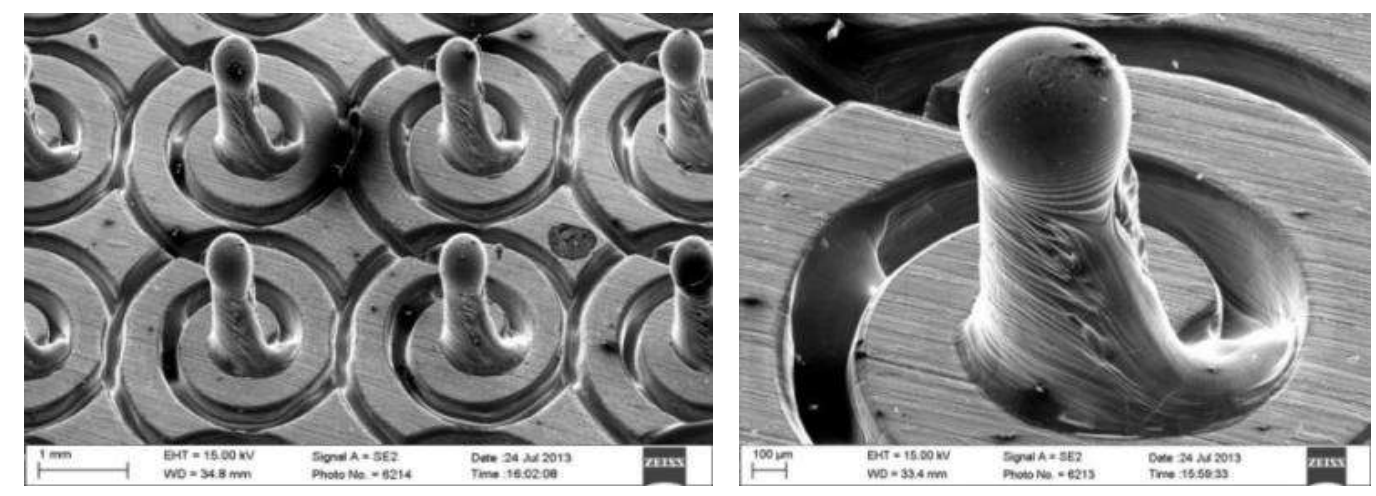

Fig.(a) Topography of specimen surface protrusions (b) Topography of single protrusion

\subsection{Microstructure and micro-hardness}

The microstructures of the protrusion (molten zone), heat affected zone (HAZ) and parent material were analysed by optical microscopy and scanning electron microscopy (SEM). These protrusions were generated by using an accelerating voltage of $150 \mathrm{kV}$, a beam current of $3.5 \mathrm{~mA}$, a scanning frequency of $1500 \mathrm{~Hz}$ and a processing time of $11 \mathrm{~s}$. The average height of protrusions was $1.5 \mathrm{~mm}$. Ti-6Al-4V specimens were etched by Kroll's reagent $(92 \mathrm{ml}$ distilled water, $6 \mathrm{ml}$ Nitric acid and $2 \mathrm{ml}$ Hydrofluoric acid) for about $20 \mathrm{~s}$. Figure 4 shows the microstructure at locations of molten zone, HAZ and parent metal. Figure $4 \mathrm{a}$ shows the cross-sectional view of the protrusion and it can be seen that the microstructure of the protrusion changed after Surfi-Sculpt processing when compared to the other zones. Figure $4 \mathrm{~b}$ further illustrates this change and a distinct interface between each zone can be identified. Figure $4 \mathrm{c}$ shows the microstructure of the HAZ and the interface between the parent metal and the HAZ. In the HAZ, a short needle shaped martensite phase with high density distribution was observed, whereas, in the microstructure of the molten 
zone as shown in Figure 4d, the distribution of the needle shaped martensitic alpha was sparser.

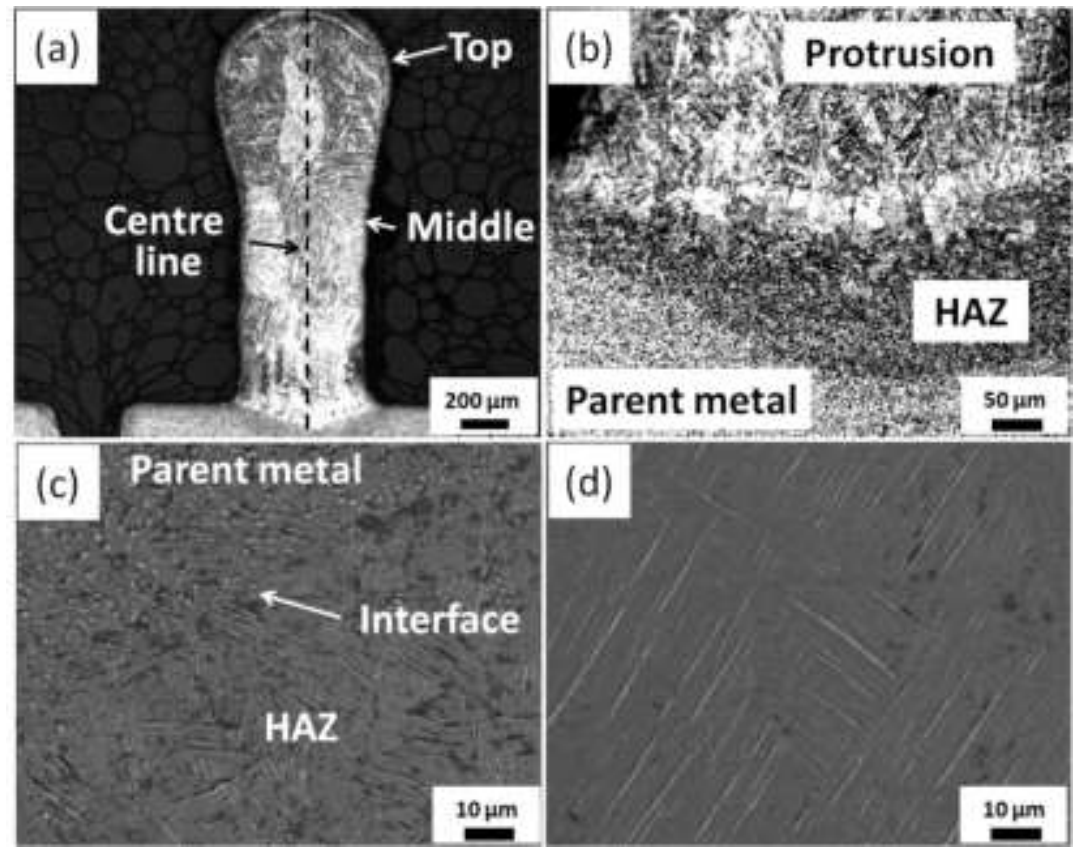

Figure 4.(a) A cross-sectional view of a resolidified molten zone after EB Surfi-Sculpt,(b) three zones are shown (parent metal, HAZ and molten zone $(200 \times)$, (c) microstructure of HAZ and the interface between the parent metal and HAZ and (d) SEM image $(1000 \times)$ of the microstructure in the molten zone where needle shaped martensite alpha phases can be observed. (Forming parameters: $150 \mathrm{kV}, 3.5 \mathrm{~mA}, 1500 \mathrm{~Hz}, 11 \mathrm{~s})$.

Figure 5 shows the weight percentage of chemical elements in locations of the molten zone (top and middle parts), HAZ and the parent metal. A large difference in aluminium content was found in the three zones: it was lower in the molten area than that in the HAZ and the parent metal, since aluminium in the molten area was vapored due to very high temperature during the Surfi-Sculpt process. Along the centre line of the protrusion the amount of aluminium was the lowest at the top and the highest at the root. Similar amount of aluminium was found in HAZ and the parent metal which was nearly equal to the typical percentage range of Ti-6Al-4V. There was little difference in vanadium amount in the molten zone (top and middle parts), HAZ and the parent metal. 


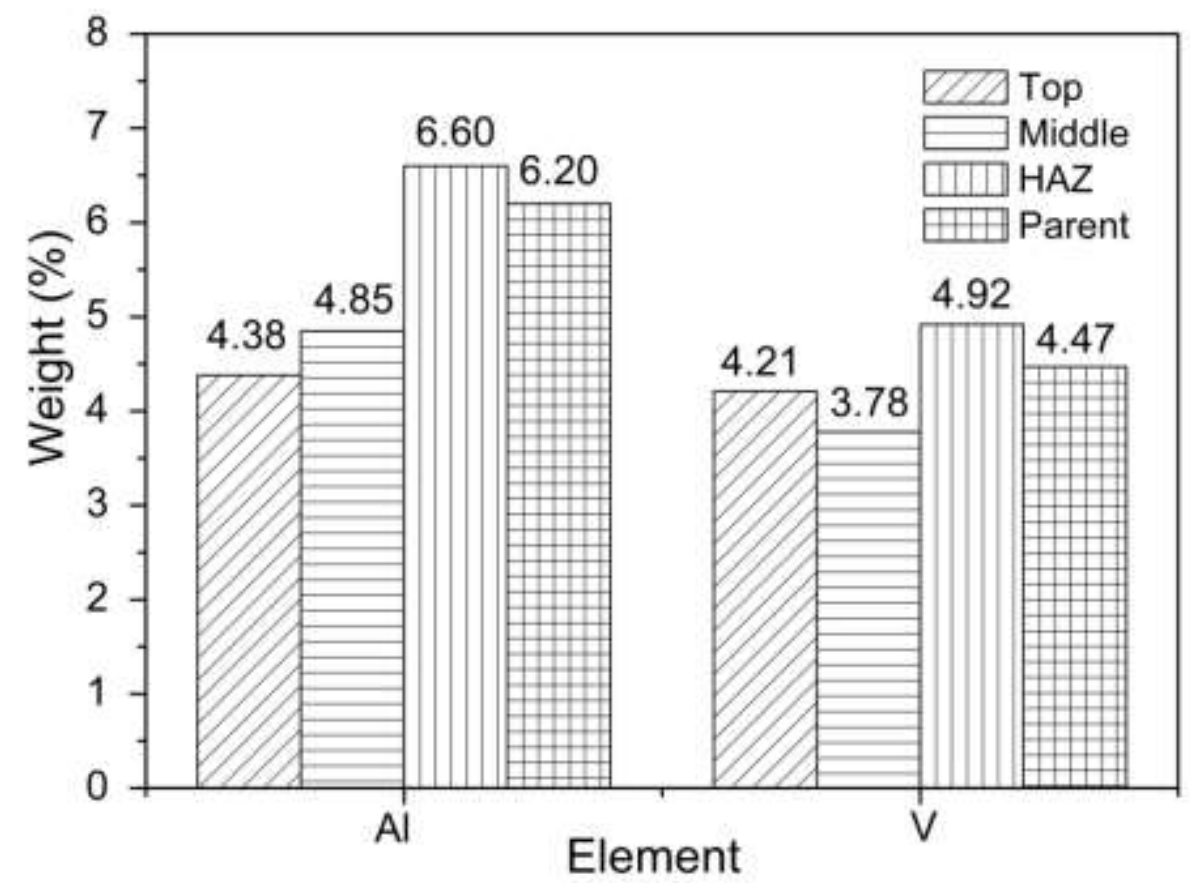

Figure 5. Weight percentage $(\%)$ of chemical elements $(\mathrm{Al}, \mathrm{V})$ in the molten zone, $\mathrm{HAZ}$ and parent metal.(Forming parameters: $150 \mathrm{kV}, 3.5 \mathrm{~mA}, 1500 \mathrm{~Hz}, 11 \mathrm{~s}$ ).

Figure6 shows the results of X-ray diffraction (XRD)after Surfi-Sculpting. Phase transformation occurred during the melting and solidification stages of the Surfi-Sculpt process. A binary phase consisting of alpha( $\alpha$, hcp Ti) and $\operatorname{beta}(\beta$, bcc Ti) phases were identified in the parent metal. When the heated substrate underwent cooling from high temperature, $\beta$ phase partially transformed to primary $\alpha$ or to martensite, $\alpha^{\prime}$ depending on the cooling rate. Figure 4 shows the transformed microstructure at different locations. However, it was difficult to distinguish between $\alpha$ and $\alpha^{\prime}$ phases directly from the XRD patterns as these two phases have the same crystal structure (hexagonal closed packed) and similar lattice parameters. 


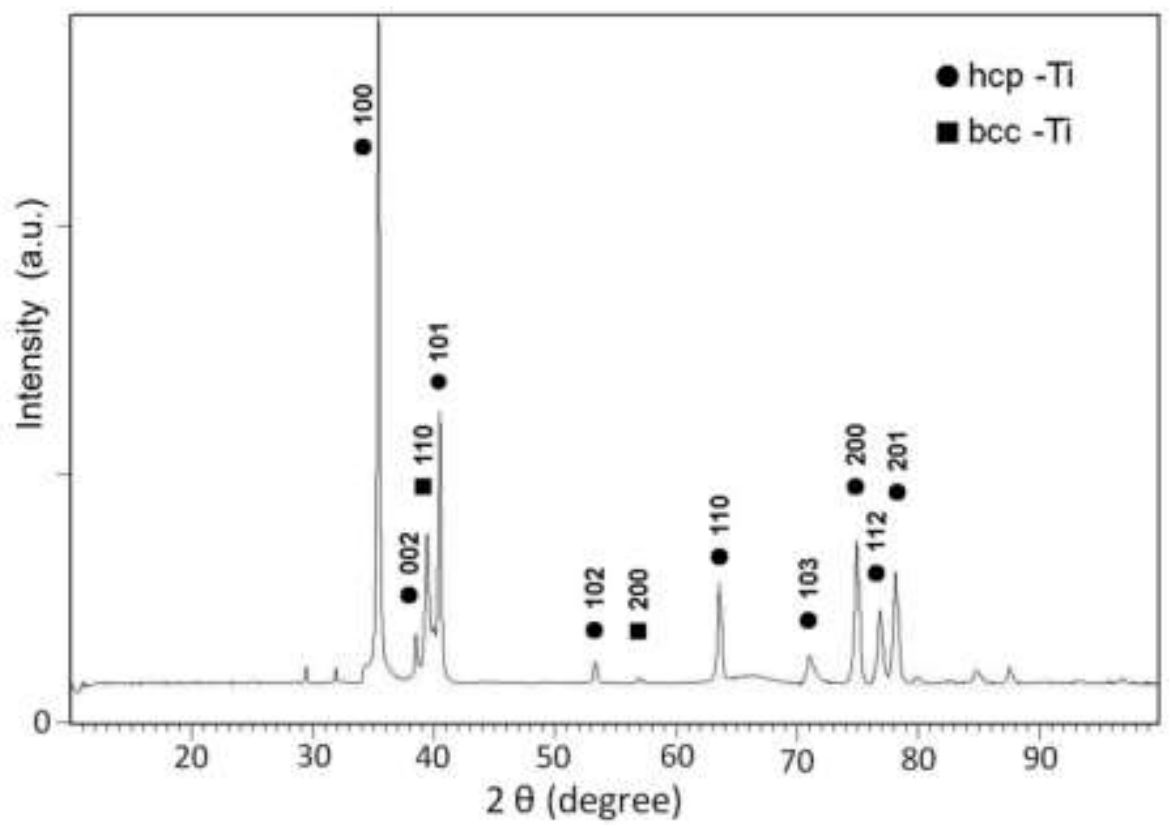

Figure 6. X-ray diffraction profiles of Ti-6Al-4V alloy. (Forming parameters: $150 \mathrm{kV}, 3.5 \mathrm{~mA}, 1500$ $\mathrm{Hz}, 11 \mathrm{~s})$.

The results from Figure 6 shows that $\alpha$ or $\alpha^{\prime}$ and $\beta$ phases were present in the specimen. At $2 \theta$ angles corresponding to $35.39^{\circ}, 40.47^{\circ}$, and $74.92^{\circ}$, peaks with (100), (101) and (200) orientations were detected for the $\alpha$ or $\alpha^{\prime}$ phase, whereas for the $\beta$ phase, a peak with (110) orientation was found at an angle of $39.41^{\circ}$ and another weaker peak with (200) orientation at angle of $56.97^{\circ}$. As shown previously from the microstructure in Figure 4 from OM and SEM analysis and literature for cooling rate of surfi-sculpt processing [22,23], the phases in the protrusion were confirmed to be a mixture of $\alpha$ or $\alpha^{\prime}$ and $\beta$ phases.

Figure 7 shows the Vickers hardness profiles along the centreline of the protrusion. The three different regions shown in Figure $4 \mathrm{~b}$ can also be identified from the hardness profile. The maximum hardness value of $428 \mathrm{HV}$ was found in HAZ. The hardness values were similar in the protrusion area and the parent metal which was about $360 \mathrm{HV}$. It is different from the trend observed in electron beam welds, in which the maximum value of hardness was found in the molten zone $[22,24]$. Within the protrusion, there was no obvious difference in the hardness value from the 
top to the bottom as the microstructure in the protrusion was a mixture of $\alpha$, needle shaped martensite $\alpha^{\prime}$ and a small fraction of $\beta$ phase. The proportion of the martensite phase which contributes to a high hardness value was relatively low as shown in Figure 4d, mainly due to repeated heating and cooling of the protrusion during processing. Hence, the similar hardness value comparable to the parent metal. On the other hand, in HAZ, a rapid heating and quenching of the substrate surface close to the protrusion root by the electron beam operating with a fast scanning speed resulted in a large proportion of the parent metal transforming into martensite and thus, increased the hardness in this region.

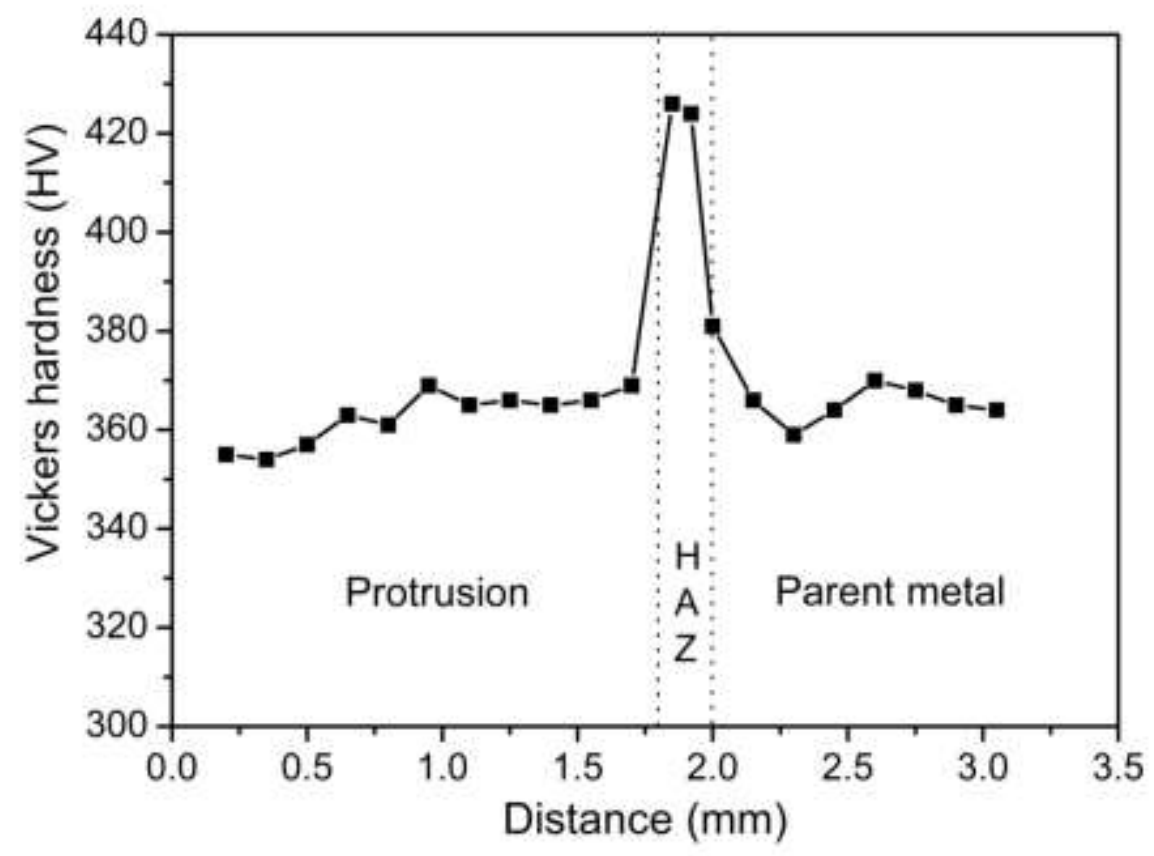

Figure 7. Vickers hardness variation across the centreline of protrusion from top to bottom, including HAZ and parent metal. (Forming parameters: $150 \mathrm{kV}, 3.5 \mathrm{~mA}, 1500 \mathrm{~Hz}, 11 \mathrm{~s}$ ). Future work and challenges:

Electron beam surfi-sculpt could be used to manufacture many types of protrusions on different materials, but more work will be also researched in the future, such as:

(1) Protrusions are obtained by flowing and forming of molten materials, when the protrusion come up, the materials nearby will be transferred, which may influence the surface uniformity and quality of the structure, consequently it is more useful in the applications of functional design or non-load 
bearing structure. While to other applications, how to decrease or evaluate the effect of surface quality by parameters optimization, for example, scanning waveform, will become a significant research question.

(2) Patterns will be needed in different applications, but it is difficult to design how to obtain them accurately by materials transferring. Simulation of fluid dynamics when molten materials transferring will be useful.

(3) Electron beam surfi-sculpt is a heating process, which lead to thermal distortion during manufacturing, especially to some very thin plate. How to control the distortion relying on the cooling condition and manufacturing sequence will be a challenge.

\section{Conclusions}

In summary, the protrusion with a higher height can be manufactured more efficiently when using abeam current of $3.5 \mathrm{~mA}$, and scanning frequency of $1500 \mathrm{~Hz}$ for Ti-6Al-4V. These parameters provided a largest protrusion growth rate. The process of transferring the molten substrate into a protrusion was a balance of the heating and cooling cycle, surface tension gradient and the viscosity of the molten metal. The microstructure of the protrusion was a mixture of primary $\alpha, \alpha^{\prime}$ and partly $\beta$ phases. The maximum hardness value of $428 \mathrm{HV}$ was found in the heat affected zone (HAZ), while the hardness values were similar in the protrusion area, whereas the hardness of parent metal was about $360 \mathrm{HV}$.

\section{Acknowledgement}

The strong support from Aviation Industry Corporation of China (AVIC) for this funded research is much appreciated. The research was performed at the AVIC Centre for Structural Design and Manufacture at Imperial College London. The authors acknowledge the financial support from 
National Natural Science Foundation of China (No.50975268), and thank Dr. David Dye of Imperial College London for the help of microstructure observation.

\section{References}

[1] B.G.I. Dance, E.J.C. Kellar. Workpiece structure modification. International patent publication number WO2004028731 A1.

[2] B.G.I. Dance, A.L. Buxton. An introduction to Surfi-Sculpt ${ }^{\circledR}$ technology - new opportunities, new challenges. Proc. ICBT (2007) 7.

[3] A.L. Buxton, B.G.I. Dance. Surfi-Sculpt - Revolutionary surface processing with an electron beam. Proc. ISEC (2005) 4.

[4] A.L. Buxton, B.G.I. Dance. The potential of EB surface processing within the aerospace industry. Rare Metal Mat Eng. 40 (2011) 155.

[5] X.C. Wang, S.L. Gong, E.M. Guo, H.Y, Zhao, H.D. Xu. Primary study on electron beam Surfi-Sculpt of Ti-6Al-4V. Adv Mat Res. 418-420 (2012) 772.

[6] X.C. Wang, E.M. Guo, S.L. Gong, B. Li. Realization and experimental analysis of electron beam Surfi-Sculpt on Ti-6Al-4V alloy. Rare Metal Mat Eng. 43 (2014) 0819.

[7] X.C. Wang, E.M. Guo, S.L. Gong, B.G.I. Dance. Study of electron beam Surfi-sculpt during composite materials joining. Rare Metal Mat Eng. 40 (2011) 292.

[8] W. Tu, P.H. Wen, P.J. Hogg, F.J. Guild. Optimisation of the protrusion geometry in Comeld ${ }^{\mathrm{TM}}$ joints. Compos. Sci. Technol. 71 (2011) 868.

[9] W. Tu, P.H. Wen, P.J. Hogg, F.J. Guild. Multi-region mesh free method for Comeld ${ }^{\mathrm{TM}}$ joints. Comp. Mater. Sci. 48 (2010) 481.

[10] H.J. Zhang, W.D. Wen, H.T. Cui. Study on the strength prediction model of Comeld composites joints. Compos. Part B-Eng. 43 (2012) 3310.

[11] G. Thomas, R. Vincent, G. Matthews, B.G.I. Dance, P.S. Grant. Interface topography and 
residual stress distributions in W coatings for fusion armour applications. Mater. Sci. Eng. A 477 (2008) 35 .

[12] A.L. Buxton, A. Ferhati, R.J.M. Glen, B.G.I. Dance, D. Mullen, T. Karayiannis. EB surface engineering for high performance heat exchangers. Proc. FIEBWC (2009) 1.

[13 ] D.W. Bechert, M. Bruse, W. Hage, J.G.T.van der Hoeven, G. Hoppe. Experiments on drag-reducing surfaces and their optimization with an adjustable geometry. J. Fluid Mech. 338 (1997) 59.

[14] S.A. Kulinich, M. Farzaneh. Ice adhesion on super-hydrophobic surfaces. Appl. Surf. Sci.255 (2009) 8153.

[15] K. Euh, J. Lee, S. Lee, Y. Koo, N.J. Kim. Microstructural modification and hardness improvement in boride/Ti-6Al-4V surface-alloyed materials fabricated by high-energy electron beam irradiation. Scripta. Mater.45 (2001) 1.

[16] A. Fedoryszyn, P. Zyzak. Characteristics of the outer surface layer in casts subjected to shot blasting treatment. Arch. Metall. Mater. 55 (2010) 813.

[17] S. Kumar, R. Singh, T.P. Singh, B.L. Sethi. Surface modification by electrical discharge machining: A review. J. Mater. Process. Technol. 209 (2009) 3675.

[18] G. Ryk, Y. Kligerman, I. Etsion. Experimental investigation of laser surface texturing for reciprocating automotive components. Tribol. T. 45 (2002) 444.

[19] S. Ucsnik, M. Scheerer, S. Zaremba, D.H. Pahr. Experimental investigation of a novel hybrid metal-composite joining technology. Compos Part A-Appl.S. 41 (2010) 369.

[20 ] C. Earl, P. Hilton, B.O'Neill. Parameter influence on Surfi-Sculpt processing efficiency. Phys Procedia. 39 ( 2012 ) 327.

[21] V. Juechter, T. Scharowsky, R.F. Singer, C. Körner. Processing window and evaporation phenomena for Ti-6Al-4V produced by selective electron beam melting. Acta. Mater.76 (2014) 252. [22] S.G. Wang, X.Q. Wu. Investigation on the microstructure and mechanical properties of 
Ti-6Al-4V alloy joints with electron beam welding. Mater. Des.36 (2012) 663.

[23] T. Ahmed, H. J. Rack. Phase transformations during cooling in $\alpha+\beta$ titanium alloys. Mater. Sci. Eng A.243 (1998) 206.

[24] W. Lu, Y.W. Shi, Y.P. Lei, X.Y. Li. Effect of electron beam welding on the microstructures and mechanical properties of thick TC4-DT alloy. Mater. Des.34 (2012) 509. 